\title{
Evaluation of palliative care patients with different scales in the emergency department and the importance of home healthcare
}

\author{
Hulya Guney', Nursah Basol² \\ 'Department of Emergency Medicine, Tokat State Hospital, Tokat, Turkey \\ ${ }^{2}$ Department of Emergency Medicine, Faculty of Medicine, Gaziosmanpasa University, Tokat, Turkey
}

\section{Abstract}

Introduction: With this comprehensive study, we aimed to contribute to the integration process of palliative care (PC) to emergency departments (ED) by determining ED patients needing PC, with the help of a new screening method and assessment with the Screen for Palliative and Endof-Life Care Needs in the emergency department (SPEED), Karnofsky performance scale (KPS), and Edmonton Symptom Assessment Scale (ESAS).

Material and methods: Patients who were admitted to the ED between 2015 and 2017 were included in this prospective study. The study form included the following variables: demographic information, duration of diagnosis, PC follow-up, consultation status, and the outcome in ED. SPEED, KPS, and ESAS were applied to the patients.

Results: The study was carried out with the participation of 150 patients. The mean score of the patients on the KPS was 43.13. The most common symptoms observed in patients were fatigue, pain, anorexia, and nausea, respectively. It was determined that patients who did not receive home healthcare were more likely to feel tired, sad, and anxious, and the SPEED levels of these patients were found to be higher.

Conclusions: The present study is the first to identify the group of ED patients requiring PC and to determine and accordingly evaluate the current state and symptoms of this patient group using scales. Accordingly, it would be a correct approach to apply ESAS and KPS to patients in order to better evaluate the symptoms present in ED. At the same time, it was determined that home healthcare services play an important role in PC.

Key words: palliative, emergency, Karnofsky performance scale, Edmonton Symptom Assessment Scale.

\section{Corresponding address:}

Dr. Nursah Basol, Department of Emergency Medicine, Faculty of Medicine,

Gaziosmanpasa University, 60100, Tokat, Turkey, phone: +90 3562129500/3418, fax: +90 356 2133179, e-mail: drnursahbs@hotmail.com

\section{INTRODUCTION}

According to the definition of the term by World Health Organisation in 2006, palliative care (PC) is an approach that improves the quality of life of patients and their families facing the problems associated with life-threatening illness, through the prevention and relief of suffering by means of early identification and impeccable assessment and treatment of pain and other problems, physical, psychosocial, and spiritual" [1]. The main principle in PC is the early recognition and symptomatic treatment of patients with advanced disease and ongoing progression, as well as applications aiming to ensure that the relatives of the patients may also overcome this process easily [2]. The enhanced importance of the necessary care and treatment provided to in- curable patients with life-threatening diseases has made it possible for $\mathrm{PC}$ to gain ground in other fields of medicine despite being a new discipline [3].

Today in Turkey there are no PC services offered by specialist groups integrated with the health system, who have received training specific to this area. In a study conducted by Wright $e t$ al. in 2006, Turkey is stated within the group of countries identified as having no structured activities of hospice/PC or yet to be sufficient in the discipline, on the map asserting the development of hospice-PC across the globe [4].

Bingley and Clark declared in a study conducted in 2008 that comparatively evaluated the development of PC services in 6 countries (Israel, Turkey, Palestine, Cyprus, Egypt, and Jordan) who were members of the Middle East Cancer Consortium (MECC), which Turkey joined in 2004; they stated 
that a total of 69 PC services were recognised between 2005 and 2006, amounting to 0.42 PC services per million individuals when divided by the total population of the member countries (162.9 million). This rate reveals the demand for PC services to a large extent in the member countries of the MECC $[5,6]$. Especially since the beginning of 2013, PC has gained importance by our Ministry of Health, and as of 2016 there are 168 PC centres with 1898 beds in 68 provinces in our country [7].

The emergency department (ED) visits of PC patients is gaining importance steadily due to the increase in elderly population and advanced stage diseases [8]. The main principle of emergency medicine is to provide immediate and precise solutions to complications; in this context, it does not fully coincide with PC [9]. While in the ED, intensive and immediate operation is always essential, it is possible for the emergency physician to provide the necessary care to this special group of patients with sufficient knowledge and skills [10, 11].

Given all this, ED is one of the indispensable components of PC. Although there are many studies abroad in the interest of accomplishing complete evaluation and treatment of PC patients in ED, studies in this area are very limited in our country. With this comprehensive study, we aimed to contribute to the integration process of PC to ED by determining the group of patients admitted to the ED, who were in need of PC with the help of a new screening method and by analysing their needs and symptom severities with the Screen for Palliative and Endof-Life Care Needs in the Emergency Department (SPEED), Karnofsky performance scale (KPS), and Edmonton Symptom Assessment Scale (ESAS).

\section{MATERIAL AND METHODS}

A total of 150 patients aged 18 years and over, who were admitted to the ED of Gaziosmanpasa University Faculty of Medicine Hospital between the dates of December $1^{\text {st }} 2015$ and February $1^{\text {st }} 2017$, were included in this prospective study, which obtained an Ethics Committee permit. In the province where the present study was conducted, there is an outpatient PC unit, a medical oncology and radiation oncology unit, and an inpatient PC service connected to the public hospital. Additionally, home healthcare services also provide care services for patients with chronic diseases. The patient group that provided the first step of the 3-step screening model belonging to a study titled "Content validation of a novel screening tool to identify emergency department patients with significant palliative care needs" was also included in our study [12].
The study form included the following variables: demographic information (age, gender) of the patients, duration of diagnosis, whether there is PC follow-up, whether they receive home healthcare services or financial support from the government due to their illness, ED follow-up duration, whether consultation is requested, and the outcome of follow-up in ED (discharge, clinical hospitalisation, intensive care unit (ICU) hospitalisation, death). In addition to this demographic information, SPEED, KPS, and ESAS were applied to the patients.

The analysis of the study was prepared using IBM SPSS 20 and Excel 2010 version. Frequency (F) and percentage values of all variables were calculated. The Kolmogorov-Smirnov test was used to test the normality assumptions of the scales. In comparative analysis, Kruskal-Wallis $H$ test, Mann-Whitney $U$ test, and Pearson $\chi^{2}$ test were used. Subsequently, a difference was observed as a result of the Kruskal-Wallis $H$ test; thereafter, the Mann-Whitney $U$ test was applied to find out from which groups the difference originated.

\section{RESULTS}

Frequency and percentage distributions of the information gathered from the patients are given in Table 1. According to this, $44 \%$ of the patients were female and $56 \%$ were male. $6.70 \%$ of the patients were between the ages of 18 and 45 years, $35.30 \%$ between the ages of 46 and 65 years, and $58 \%$ were aged 66 years and over. $30 \%$ of the patients had PC unit follow-up. It was observed that $27.30 \%$ of the patients received home healthcare services. $28.70 \%$ of the patients stated that they received financial support from the government due to their illness. It was determined that after admission to the hospital, $42.70 \%$ of patients stayed between 1 and 4 hours in the ED and $57.30 \%$ between 4 and 24 hours. Consultation was requested for $59.30 \%$ of the patients. $51.3 \%$ of patients visiting the ED were discharged, $34 \%$ were hospitalised in the ED and $13.3 \%$ in the ICU, while $1.3 \%$ of the patients died.

The mean \pm standard deviation value of the scores obtained by the patients on the KPS scale was calculated as $43.13 \pm 13.86$. It was observed that the patients were predominantly in need of constant special help and care.

Patients were evaluated according to ESAS. Accordingly, fatigue in $88.7 \%$ of patients, pain in $74 \%$, anorexia in $72 \%$, nausea in $64 \%$, sadness in $60.7 \%$, anxiety in $60 \%$, insomnia in $54.7 \%$, dyspnoea in $51.3 \%$, numbness in the hands of $40.7 \%$, mouth sore in $36.7 \%$, and changes in the skin and nails in $26.7 \%$ were observed. The findings of the Mann-Whitney $\mathrm{U}$ test performed for the comparison of ESAS in 
Table 1. General info of patients

\begin{tabular}{|c|c|c|}
\hline Parameter & $\mathbf{F}$ & $\%$ \\
\hline \multicolumn{3}{|l|}{ Gender } \\
\hline Female & 66 & 44.00 \\
\hline Male & 84 & 56.00 \\
\hline \multicolumn{3}{|l|}{ Age (years) } \\
\hline $18-45$ & 10 & 6.70 \\
\hline $46-65$ & 53 & 35.30 \\
\hline 66 and over & 87 & 58.00 \\
\hline \multicolumn{3}{|l|}{ Diagnosis } \\
\hline Advanced dementia or CNS disease & 39 & 26.00 \\
\hline Cancer & 82 & 54.66 \\
\hline ESRD & 8 & 5.33 \\
\hline End-stage COPD (stage 4) & 5 & 3.33 \\
\hline End-stage cardiac failure & 3 & 2.00 \\
\hline ESLD & 10 & 6.66 \\
\hline Septic shock, multiple organ failure & 0 & 0 \\
\hline Other & 3 & 2.00 \\
\hline \multicolumn{3}{|l|}{ Time of diagnosis } \\
\hline Less than 6 months & 31 & 20.70 \\
\hline 6 months -5 years & 81 & 54.00 \\
\hline More than 5 years & 38 & 25.30 \\
\hline \multicolumn{3}{|l|}{ PC unit follow-up } \\
\hline Yes & 45 & 30.00 \\
\hline No & 105 & 70.00 \\
\hline \multicolumn{3}{|l|}{ Reason for no follow-up } \\
\hline Not aware of PC services & 97 & 92.38 \\
\hline Other & 8 & 7.61 \\
\hline \multicolumn{3}{|l|}{ Home healthcare services receival status } \\
\hline Yes & 41 & 27.30 \\
\hline No & 109 & 72.70 \\
\hline \multicolumn{3}{|l|}{ Financial government support } \\
\hline Yes & 43 & 28.70 \\
\hline No & 107 & 71.30 \\
\hline \multicolumn{3}{|l|}{ Care giver } \\
\hline $1^{\text {st }}$ degree relative & 147 & 98.00 \\
\hline Other & 3 & 2.00 \\
\hline \multicolumn{3}{|l|}{ Existence of any other disease } \\
\hline Yes & 83 & 55.30 \\
\hline No & 67 & 44.70 \\
\hline \multicolumn{3}{|l|}{ Duration of stay in ED } \\
\hline $1-4$ hours & 64 & 42.70 \\
\hline $4-24$ hours & 86 & 57.30 \\
\hline \multicolumn{3}{|l|}{ Consultation status } \\
\hline Yes & 89 & 59.30 \\
\hline No & 61 & 40.70 \\
\hline \multicolumn{3}{|l|}{ Outcome } \\
\hline Discharge & 77 & 51.30 \\
\hline Clinical hospitalisation & 51 & 34.00 \\
\hline Intensive care hospitalisation & 20 & 13.30 \\
\hline Death & 2 & 1.30 \\
\hline
\end{tabular}

F - frequency, CNS - central nervous system, ESRD - end-stage renal disease, COPD - chronic obstructive pulmonary disease, ESLD - endstage liver disease, PC - palliative care, ED - emergency department. terms of KPS are given below (Table 1). The difference between the average scores of patients used for determining KPS and the average rankings of the following ESAS: dyspnoea $(p=0.014<0.05)$, changes in the skin and nails $(p=0.045<0.05)$, and numbness in the hands ( $p=0.012<0.05)$, was statistically significant. According to the findings, KPS of patients without dyspnoea, changes in the skin and nails, and numbness in the hands were higher than the observed patients.

The findings of comparing the ESAS info of the patients using Pearson $\chi^{2}$ test according to their status of receiving home healthcare services are given in Table 2.

It was determined that the percentage of patients experiencing sadness was $43.90 \%$ in those receiving home healthcare services, while it was $67 \%$ in patients who did not receive home healthcare services $(p=0.010<0.05)$. It was observed that $43.90 \%$ of the patients who received home healthcare services and $66.10 \%$ of the patients who did not receive home healthcare services felt anxiety $(p=0.014<0.05)$. Dyspnoea was present in $65.90 \%$ of patients who received home healthcare services and in $45.90 \%$ of patients who did not $(p=0.029<0.05)$. Numbness in the hands was an experienced symptom in $53.70 \%$ of the patients who received home healthcare services and in $35.80 \%$ of the patients who did not $(p=0.047<0.05)$. Results of the Pearson $\chi^{2}$ test performed showed that there was a statistically significant difference between patients who received and did not receive home healthcare services, in terms of feeling sad and anxious, having dyspnoea, and experiencing numbness in the hands (Table 3).

The results of the Mann-Whitney $U$ test performed to compare the SPEED scores of patients in terms of their home healthcare service receival status are presented below (Table 4). As a result of the MannWhitney $U$ test, the difference between the mean score of the patients for determining the SPEED and the average of rankings regarding whether they receive home healthcare services or not was found to be statistically significant $(p=0.015<0.05)$. According to the findings, it was found that patients who received home healthcare services at home had higher SPEED performance scores.

\section{DISCUSSION}

Palliative care, despite being a new discipline, has rapidly established itself in other fields of medicine. The foremost reason for the rapid development of this movement is that it is becoming increasingly crucial today to provide the necessary care and treatment to life-threatening and untreatable patients [13]. At present, ED admissions of PC patients 
Table 2. Findings regarding comparison of Edmonton Symptom Assessment Scale data according to home healthcare service receival status of patients

\begin{tabular}{|c|c|c|c|c|c|c|c|}
\hline Symptoms & Groups & $\begin{array}{c}\text { F (receives home } \\
\text { healthcare } \\
\text { services) }\end{array}$ & $\begin{array}{c}\text { F (does not receive } \\
\text { home healthcare } \\
\text { services) }\end{array}$ & $\begin{array}{c}\% \text { (receives } \\
\text { home healthcare } \\
\text { services) }\end{array}$ & $\begin{array}{c}\% \text { (does not receive } \\
\text { home healthcare } \\
\text { services) }\end{array}$ & $P$-value & $\chi^{2}$ \\
\hline \multirow[t]{2}{*}{ Pain } & Yes & 28 & 83 & 68.30 & 76.10 & \multirow[t]{2}{*}{0.328} & \multirow[t]{2}{*}{0.955} \\
\hline & No & 13 & 26 & 31.70 & 23.90 & & \\
\hline \multirow[t]{2}{*}{ Fatigue } & Yes & 31 & 102 & 75.60 & 93.60 & \multirow[t]{2}{*}{0.002} & \multirow[t]{2}{*}{9.572} \\
\hline & No & 10 & 7 & 24.40 & 6.40 & & \\
\hline \multirow[t]{2}{*}{ Nausea } & Yes & 25 & 71 & 61.00 & 65.10 & \multirow[t]{2}{*}{0.636} & \multirow[t]{2}{*}{0.224} \\
\hline & No & 16 & 38 & 39.00 & 34.90 & & \\
\hline \multirow[t]{2}{*}{ Sadness } & Yes & 18 & 73 & 43.90 & 67.00 & \multirow[t]{2}{*}{0.010} & \multirow[t]{2}{*}{6.645} \\
\hline & No & 23 & 36 & 56.10 & 33.00 & & \\
\hline \multirow[t]{2}{*}{ Anxiety } & Yes & $43.90 \%$ & $66.10 \%$ & 43.90 & 66.10 & \multirow[t]{2}{*}{0.014} & \multirow[t]{2}{*}{6.092} \\
\hline & No & 23 & 37 & 56.10 & 33.90 & & \\
\hline \multirow[t]{2}{*}{ Insomnia } & Yes & 21 & 61 & 51.20 & 56.00 & \multirow[t]{2}{*}{0.603} & \multirow[t]{2}{*}{0.271} \\
\hline & No & 20 & 48 & 48.80 & 44.00 & & \\
\hline \multirow[t]{2}{*}{ Anorexia } & Yes & 30 & 78 & 73.20 & 71.60 & \multirow[t]{2}{*}{0.845} & \multirow[t]{2}{*}{0.038} \\
\hline & No & 11 & 31 & 26.80 & 28.40 & & \\
\hline \multirow[t]{2}{*}{ Dyspnoea } & Yes & 27 & 50 & 65.90 & 45.90 & \multirow[t]{2}{*}{0.029} & \multirow[t]{2}{*}{4.762} \\
\hline & No & 14 & 59 & 34.10 & 54.10 & & \\
\hline \multirow{2}{*}{$\begin{array}{l}\text { Change } \\
\text { in skin } \\
\text { and nails }\end{array}$} & Yes & 12 & 28 & 29.30 & 25.70 & \multirow[t]{2}{*}{0.659} & \multirow[t]{2}{*}{0.195} \\
\hline & No & 29 & 81 & 70.70 & 74.30 & & \\
\hline \multirow[t]{2}{*}{ Mouth sore } & Yes & 16 & 39 & 39.00 & 35.80 & \multirow[t]{2}{*}{0.713} & \multirow[t]{2}{*}{0.135} \\
\hline & No & 25 & 70 & 61.00 & 64.20 & & \\
\hline \multirow{2}{*}{$\begin{array}{l}\text { Numbness } \\
\text { in the hands }\end{array}$} & Yes & 22 & 39 & 53.70 & 35.80 & \multirow[t]{2}{*}{0.047} & \multirow[t]{2}{*}{3.947} \\
\hline & No & 19 & 70 & 46.30 & 64.20 & & \\
\hline
\end{tabular}

F-frequency.

is gaining importance day by day due to the increase in the elderly population [14]. In our study, in accordance with the literature, the vast majority of patients were aged 66 years and over $[14,15]$.

Pursuant to comparing ESAS by age, the feeling of nausea in patients varied in accordance with their age. As a result of the evaluation regarding the feeling of sadness and anxiety, it was determined that patients aged 66 years and over had less sense of sadness and anxiety compared to patients in other age groups. Considering the current socio-cultural and religious structure of our country, it can be an indication that the idea of fate and submission predominates with age, and as a result the consequences arising from the disease are accepted with less difficultly.

In our country, PC is a relatively recent subject, and its evolution is yet to be completed. In a study conducted by Turgay et al., $53.7 \%$ of healthcare professionals stated that they did not receive PC-related training, and in the same study, the specialists argued that PC services should only be provided on a hospital basis [16]. Since 2013, innovations in this field have taken place in our country, and PC units have been introduced to hospitals. Although there are two PC units in our city, in the present study it was found that the majority of patients did not receive PC follow-ups and further investigation revealed the reason to be that patients were not informed about these centres. This is an indication that as yet there is no public awareness about PC. First and foremost, PC education in Faculties of Medicine may help raise the awareness among physicians, and providing information about PC through public education may increase the use of existing centres.

Palliative care patients complain of many symptoms caused by the disease itself or the treatment [17]. The symptoms with which these patients are presented to the ED include pain, shortness of breath, major bleeding, acute function loss, bleeding, seizure, and delirium [18]. In a study, it was reported that PC patients were most frequently admitted to ED with complaints of pain, nausea, vomiting, fatigue, and insomnia; while in a study conducted by Weise et al., it was noted that the most common complaints were mainly respiratory distress followed by pain, syncope, and fractures $[19,20]$. Although pain was stated among the most common symptoms in the aforementioned studies, in the present study, 
Table 3. Comparison of Edmonton Symptom Assessment Scale in terms of Karnofsky performance scale

\begin{tabular}{|c|c|c|c|c|c|}
\hline Symptoms & Groups & $n$ & Ranking & $\begin{array}{c}\text { Mann- } \\
\text { Whitney } \\
\text { U test }\end{array}$ & $P$-value \\
\hline \multirow[t]{2}{*}{ Pain } & Yes & 111 & 74.50 & \multirow[t]{2}{*}{2054} & \multirow[t]{2}{*}{0.629} \\
\hline & No & 39 & 78.33 & & \\
\hline \multirow[t]{2}{*}{ Fatigue } & Yes & 133 & 77.50 & \multirow[t]{2}{*}{865} & \multirow[t]{2}{*}{0.108} \\
\hline & No & 17 & 59.88 & & \\
\hline \multirow[t]{2}{*}{ Nausea } & Yes & 96 & 75.81 & \multirow[t]{2}{*}{2652.5} & \multirow[t]{2}{*}{0.906} \\
\hline & No & 54 & 74.95 & & \\
\hline \multirow[t]{2}{*}{ Sadness } & Yes & 91 & 77.13 & \multirow[t]{2}{*}{2536} & \multirow[t]{2}{*}{0.559} \\
\hline & No & 59 & 72.98 & & \\
\hline \multirow[t]{2}{*}{ Anxiety } & Yes & 90 & 76.54 & \multirow[t]{2}{*}{2606.5} & \multirow[t]{2}{*}{0.714} \\
\hline & No & 60 & 73.94 & & \\
\hline \multirow[t]{2}{*}{ Insomnia } & Yes & 82 & 74.70 & \multirow[t]{2}{*}{2722} & \multirow[t]{2}{*}{0.799} \\
\hline & No & 68 & 76.47 & & \\
\hline \multirow[t]{2}{*}{ Anorexia } & Yes & 108 & 72.07 & \multirow[t]{2}{*}{1898} & \multirow[t]{2}{*}{0.114} \\
\hline & No & 42 & 84.31 & & \\
\hline \multirow[t]{2}{*}{ Dyspnoea } & Yes & 77 & 84.19 & \multirow[t]{2}{*}{2171} & \multirow[t]{2}{*}{0.014} \\
\hline & No & 73 & 67.26 & & \\
\hline \multirow{2}{*}{$\begin{array}{l}\text { Change } \\
\text { in skin } \\
\text { and nails }\end{array}$} & Yes & 40 & 79.96 & \multirow[t]{2}{*}{1738.5} & \multirow[t]{2}{*}{0.045} \\
\hline & No & 110 & 63.70 & & \\
\hline \multirow[t]{2}{*}{ Mouth sore } & Yes & 55 & 68.02 & \multirow[t]{2}{*}{2201} & \multirow[t]{2}{*}{0.101} \\
\hline & No & 95 & 79.83 & & \\
\hline \multirow{2}{*}{$\begin{array}{l}\text { Numbness } \\
\text { in the hands }\end{array}$} & Yes & 61 & 82.97 & \multirow[t]{2}{*}{2072} & \multirow[t]{2}{*}{0.012} \\
\hline & No & 89 & 64.72 & & \\
\hline
\end{tabular}

Table 4. Comparison of Screen for Palliative and End-of-Life Care Needs in the emergency department scale according to home healthcare service receival status of patients

\begin{tabular}{lcccc}
$\begin{array}{l}\text { SPEED } \\
\text { performance } \\
\text { scale }\end{array}$ & $\mathbf{n}$ & Ranking & $\begin{array}{c}\text { Mann- } \\
\text { Whitney } \\
\text { U test }\end{array}$ & P-value \\
$\begin{array}{l}\text { Receives home } \\
\text { healthcare } \\
\text { services }\end{array}$ & 41 & 89.60 & 1656.5 & 0.015 \\
\hline $\begin{array}{l}\text { Does not receive } \\
\text { home healthcare } \\
\text { services }\end{array}$ & 109 & 70.20 & & \\
\hline
\end{tabular}

SPEED - Screen for Palliative and End-of-Life Care Needs in the emergency department.

it was found that the most common symptom in patients was asthaenia $(88.70 \%)$, followed by pain and anorexia $(74.00 \%, 72.00 \%)$. These findings coincide with a study conducted by Süren et al. [21]. Although in the literature there are not many studies to make a thorough comparison, it can be said that the patients taking part in the present study are more efficient in pain management compared to other studies.

When patients are evaluated with KPS, it is seen that a significant ratio of them need constant special help and care. Although in the literature there is no consensus on the determination of patients in need of PC, there is an agreement that it is unfit to limit PC to only end-of-life care. However, our findings suggest that the need for PC is most frequently associated with the terminal period of disease by our society. Public education and briefings on PC can help solve this problem [22].

The Edmonton Symptom Assessment Scale data were evaluated in terms of KPS. In view of this, patients with dyspnoea, changes in the skin and nails, and numbness in the hands appeared to have a lower KPS score compared to patients who did not experience these symptoms. According to the results, shortness of breath is observed to decrease the performance of patients considerably. This complication can be improved by providing oxygen therapy at home to patients in need. In a study, it was reported that need for supplemental oxygen in patients is one of the leading reasons for admission to the ED [20]. Regarding the principles of PC, it does not aim to ensure that every patient is admitted to the hospital. In this sense, the presence of home healthcare services provides convenience for our country. Once patients start to benefit from this system, procedures such as IV medication and bladder probe replacement can be provided with home care, as well as help dismissing the sense of forlornness and anxiety of patients. Similarly, in our study, as a result of comparing the ESAS according to whether they received home healthcare services or not, it was determined that patients who did not receive home healthcare services felt more tired, sad, and anxious. In the present study, it was also seen that the patients who received home healthcare services had higher SPEED performance scores. It was reported in a study that patients who received home healthcare services preferred to die at home and had a lower ratio of ED admissions [23]. In a study conducted by Weise et al., it was observed that most of the PC follow-up patients with cancer, who called emergency services with crisis symptoms wished to continue their care at home instead of being admitted to an ED [20]. In a study conducted by Basol et al., it was observed that among late-stage cancer patients, the rate of recurrent applicants for ED not receiving PC services is higher than those receiving these services [24]. The main issue concerning PC patients is that if they do not have a certain physician monitoring them, they feel a sense of forlornness. The aforementioned condition contributes to an increase in ED admissions. Home healthcare services play an important role in dispelling this sense of forlornness. As our study demonstrates, receiving home care services significantly reduces the feeling of sadness and anxiety in patients. Home healthcare is a crucial component of all the recommended PC systems. 


\section{CONCLUSIONS}

The present study is the first to define the patient group who were admitted to the ED and were in need of PC, and to evaluate the current state and symptoms of this patient group with scales. Accordingly, it would be a correct approach to apply ESAS and KPS to patients in order to better evaluate the symptoms present in the ED. At the same time, it was determined that home healthcare services play an important role in PC.

The authors declare no conflict of interest.

\section{REFERENCES}

1. World Health Organization. Definition of palliative care. [Internet]. [cited 2011 September 22]. Available from: www.who.int/ cancer/ palliative/definition/en. 2010.

2. Nauck F, Alt-Epping B. Crises in palliative care - a comprehensive approach. Lancet Oncol 2008; 9: 1086-1091.

3. Başol $\mathrm{N}$. The integration of palliative care into the emergency department. Türkiye Acil Tıp Dergisi 2015; 15: 100-107.

4. Wright M, Wood J, Lynch T, et al. Mapping levels of palliative care development: a global view. J Pain Symptom Manage 2008; 35: 469-485.

5. Bingley A, Clark D. A comparative review of palliative care development in six countries represented by the Middle East Cancer Consortium (MECC). J Pain Symptom Manage 2009; 37: 287-296.

6. Bingley AF, McDermott E, Thomas C, et al. Making sense of dying: a review of narratives written since 1950 by people facing death from cancer and other diseases. Palliat Med 2006; 20: 183-195.

7. Kıvanç MM. Türkiye'de palyatif bakım hizmetleri (palliative care services in Turkey). Sağlik Bilimleri Meslekleri Dergisi HSP 2017; 4:132-135.

8. McNamara BA, Rosenwax LK, Murray K, et al. Early admission to community-based palliative care reduces use of emergency departments in the ninety days before death. J Palliat Med 2013; 16: 774-779.

9. Lamba S, Desandre PL, Todd KH, et al. The improving palliative care in emergency medicine board. Integration of palliative care into emergency medicine: the improving palliative care in emergency medicine (IPAL-EM) collaboration. J Emerg Med 2014; 46: 264-270.

10. Meo N, Hwang U, Morrison RS. Resident perceptions of palliative care training in the emergency department. J Palliat Med 2011; 14: 548-555.

11. Stone SC, Mohanty S, Grudzen CR, et al. Emergency medicine physicians' perspectives of providing palliative care in an emergency department. J Palliat Med 2011; 14: 1333-1338.

12. George N, Barrett N, McPeake L, et al. Content validation of a novel screening tool to identify emergency department patients with significant palliative care needs. Acad Emerg Med 2015; 22: 823-837.

13. Kenen J. Palliative care in the emergency department: new specialty weaving into acute care fabric. Ann Emerg Med 2010; 56: A17-A19.

14. Smith AK, McCarthy E, Weber E, et al. Half of older Americans seen in emergency department in last month of life; most admitted to hospital, and many die there. Health Aff (Millwood) 2012; 31: 1277-1285.
15. Hjermstad MJ, Kolflaath J, Løkken AO, et al. Are emergency admissions in palliative cancer care always necessary? Results from a descriptive study. BMJ Open 2013; 3: e002515.

16. Turgay G, Kav S. Turkish healthcare professionals' views on palliative care. J Palliat Care 2012; 28: 267-273.

17. Oh $\mathrm{H}$, Seo $\mathrm{Y}$, Jeong $\mathrm{H}$, et al. The identification of multiple symptom clusters and their effects on functional performance in cancer patients. J Clin Nurs 2012; 21: 2832-2842.

18. Schrijvers D, van Fraeyenhove F. Emergencies in palliative care. Cancer J 2010; 16: 514-520.

19. Shin SH, Hui D, Chisholm GB, et al. Characteristics and outcomes of patients admitted to the acute palliative care unit from the emergency center. J Pain Symptom Manage 2014; 47: 1028-1034.

20. Wiese CH, Vossen-Wellmann A, Morgenthal HC, et al. Emergency calls and need for emergency care in patients looked after by a palliative care team: retrospective interview study with bereaved relatives. BMC Palliative Care 2008; 7: 11.

21. Süren M, Doğru S, Önder Y, et al. Son dönem kanser hastalarında semptom kümelerinin incelenmesi (The evaluation of the symptom clusters in patients with the diagnosis of terminal stage cancer). Agri 2015; 27: 12-17.

22. Basol N, Çelenk Y, Okan İ. Thoughts of emergency physicians about palliative care: evaluation of awareness. J Acad Emerg Med 2015; 14: 75-78.

23. Brumley R, Enguidanos S, Jamison P, et al. Increased satisfaction with care and lower costs: results of a randomized trial of in home palliative care. J Am Geriat Soc 2007; 55: 993-1000.

24. Başol N, Çeltek N, Alatli T, et al. Evaluation of terminal-stage cancer patients needing palliative care in the emergency department. J Acad Emerg Med 2015; 14: 12-15. 